\title{
The Method and Practice of University Students' Creative Education
}

\author{
Shuguang Liu, Bo Dong, and Yan Sun
}

School of Electronic and Information Eng. Xi'an Polytechnic University, Xi'an 710048, China

email: L_shuguang@yahoo.com

Keywords: University Students; Innovative Education; Connotation

\begin{abstract}
The innovative education of university students is an important measure to implement the party's education policy and the country's strategy of "the national talented personnel power" and to build innovation-oriented country, and it is also an important breakthrough to comprehensively promote the education for all-round development and to improve the personnel training quality. In-depth study of the creative educational content and features based on the theory of innovation and education, method and practice.
\end{abstract}

\section{Connotations and Characteristics of an Innovative Education}

\section{A. Creative educational content}

Innovation, is true and accurate accumulation predecessors knows is acquired on the basis of the extension of the unknown kingdom, is the sublimation of human civilization, a qualitative leap in the realm of life. The so-called innovative education, is the specific application of the concept of innovation in the field of education, it refers to the use of innovative theories, follow the law and students' innovative quality of the innovation activities of the law, in order to explore the creative potential of the people, carry forward the spirit of the human subject, to promote harmonious development of human personality for the purpose, to train students to have a certain sense of innovation, creativity, innovation, innovative capability and innovative personality as the basic value orientation, and continues to use the new knowledge, new technologies, new ideas, new materials, the rapid conversion Productivity as the goal of a new educational theories and models. Innovative Education In short, the main goals of education is to cultivate innovative talents, it is the mainstream of the development of 21st century education, but also to show the idealized education of the highest human nature.

\section{B. Characteristics of innovative education}

First, open up. Innovative education that innovation is a characteristic of human nature, the object of education is a living value innovation; even if the person inherits, inducing innovation is in line with human nature and social nature of education. Schools to teach not only the knowledge is more important is the moral, cultural, identified the trial, the use of restructuring and beyond. Educational activities should focus on innovative Spirit and creative abilities, to foster innovation and personality as the basic goal. Promote innovative education, it is necessary to go beyond the basis of inheritance, to adapt to the conditions under development, educational innovation [1].

The second is active. The innovation is in hard labor and social practice, the operation of the intellect physical practice, there would be no innovation. Not only the ability to innovate, innovative spirit in practical activities to generate and development. Claims of innovation and education activities to learn the main independent, dynamic, and explore the description section of the activities. Activities to guide students to hands-on, minds, animals, and moving, to motivate students to challenge, integrating the new structure, individuality, independent and enterprising.

The third is social. Everyone has the innovation was all the time with the creation of the machine. Must adhere to the education for all, the passion for innovation and opportunities given to each student, according to different characteristics, abilities, so that they have the innovative spirit and ability. Should be encouraged to learn from each other, coordinating groups, adhere to the scientific direction, emphasizing the social orientation of the innovation, and strive to see the 
effectiveness of socialist three civilizations

The fourth is the difference. People have the potential of innovation, but innovation on the type and level. Because congenital especially acquired conditions, each field of innovative, quality, speed, performance will be different. Can not use a fixed mode to "batch create" innovative in vivo. You must insist on respect for individuality, abilities, and to allow and support the students in the select key provisions of the syllabus, learning the procedures and methods, and incentives coming to the fore and innovation. To promote good personality formation, scientific treatment of personality characteristics, counseling aggressive and favorable personality become the students' own characteristics.

\section{Theories and Methods of an Innovation Education}

Innovation education's theoretical system should include at least: five aspects of the establishment of the Students' innovative ideas, innovation and the accumulation of knowledge, innovative approach to learning, innovation ability and creative personality shape, etc. ${ }^{[2]}$.

\section{A. Students establishment of innovative ideas}

The concept is the precursor of action. The successful implementation of innovative education, first get the great value of the depth of creative educators and the educated and the whole society every citizen heart. Innovation and education to make students and teachers can recognize that innovation is the highest expression and characterization of human nature forces, the development of creativity is to safeguard human vocation, the soul of modern education.

Therefore, from the level of innovative ideas, the first is the innovative sense is respected innovation, the pursuit of innovation, and take pride in innovation and awareness of culture. Only under the guidance of the strong sense of innovation, people may have strong motivation of innovation to foster innovation goals, and give full play to the potential for innovation and ingenuity. Followed by the cultivation of innovation and emotion. The innovation process is not just a purely intellectual process, it also needs innovation and emotion as a driving force, such lofty ideals, a strong faith and a strong passion for innovation factors. The role of the double emotional factors of intelligence and innovation, people innovation is only possible to obtain the combined effect. Once again, the cultivation of innovative thinking. It is invented or discovered a new way to deal with something of the thought process is the key to the entire innovation activities and smart structures, the core of the innovation capability. Innovation is produced in the passion driven by conscious thinking, creative thinking is the realm of spirit of love, the pursuit, struggle and dedication to the formation of highly concentrated, immersed in that kind of environment conscious thinking. This is the United States Peter • Senge in improving mental models ${ }^{[3]}$.

\section{B. Students innovative accumulation of knowledge}

Innovation can not do without the support of knowledge, good knowledge of the innovation system is the basis of innovation and education. Scientific knowledge is that people understand the world and transform the world a prerequisite, a necessary foundation for the people of innovation activities; and the accumulation of knowledge to promote the strengthening of people's innovation capacity. Reserves of knowledge in knowledge in the mind of a more space and freedom of thinking behind the initiative, more and more opportunities for creative vision into creative thinking of the possibility of the outcome of the

Is worth noting that the human cognitive ability as the practice is constantly evolving to improve the scientific knowledge constantly changes. The one hand, new ideas, new discoveries, new inventions and new management model constantly enrich the treasure house of human knowledge; the other hand, the new practice test, some old ideas and conclusions, a discard. Thus for the study of knowledge, there are two types: one is to maintain learning, its function is to access to existing knowledge, experience, and to improve the ability to solve the current problem; another innovative learning, it function is through learning, to improve a person found to absorb new information and new issues are raised to meet to deal with rapid changes of the good society. College students the 
preparation of innovative knowledge and learning, apparently only the latter. Through creative learning, cross-learning, exploratory learning, research and learning, critical learning, to guide students to create a unique knowledge structure, so that solid foundation, Arts and blend, have the spirit of both scientific and humanities, creative. Innovative thinking is always growing above the distinctive knowledge structure.

\section{Students innovative approaches to learning}

Innovation is both an objective process of practice, but also a micro-psychological process, its complexity, there must be the right way and a good way. Founder of the sociology of science, Bernard said: "good way to make us better able to play and use the talents, the poor may impede in order to play. Therefore, scientifically valuable knowledge and innovative talent, because of methodological poor may be weakened, or even be stifled; the good growth, to promote such talent.

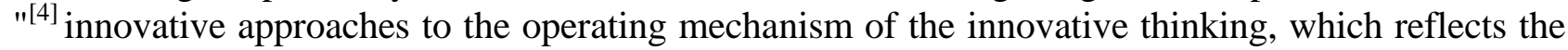
behavior in innovation activities innovative body movement skills and abilities. It includes the innovation of innovative information, material processing capacity, operating capacity, the expressive power of innovation. Through innovative approaches to learning and training can improve the speed of the college students thinking, to broaden the breadth of thinking, to extend the depth of thinking, to achieve the purpose of cultivating students' creative thinking and innovation capability.

\section{The cultivation of students' innovative ability}

Developing innovation capability is the key to Innovation Education. Innovation capability is the mastery of knowledge, application of knowledge, innovative skills in observation, reflection activities on the basis of the formation of the. Innovation capability is the performance of human intelligence activities. It is the product of the combination of cognitive ability and practical ability, it is human to create their own intelligence and to create a combination of character.

The ability to structure creative talents, mainly consists of two elements of the general ability to innovate and special innovation capability. General innovation capacity refers to the ability to work in all areas of innovation, is the most common capacity system in representing the level of mental ability of innovators, creative observation and creative thinking ability is the most important elements of capacity. Innovation in education to develop students' creative ability to observe, to strengthen the students found unexpected and dynamic observation circuitous observation, changing the perspective and the experimental observation skills, so that it can see other people did not see things, and thinking of others have not thought about problem. Creative thinking ability of the core elements of the general innovation capability is the most prominent characteristic of the thinking of the creative talents. Creative thinking ability and strive to find new problems to solve new problems. Special ability to innovate is an important component in the system of innovation capability is a necessary condition to engage in creative activities. Including those engaged in specific activities must have the academic abilities and expertise. For example, engaged in the innovative design of the mechanical and electrical products, mechanical design capabilities, the ability of computer-aided design, mechanical and electrical testing capabilities, making the sample prototype craft skills. Clearly, the pedagogical or professional teaching is the main way to cultivate this ability.

\section{E. College Students' Creative Personality}

Personality is formed by the physiological genetic and acquired experience, contains a variety of psychological factors and objective conditions change, a relatively stable internal behavior and external behavior of a unified reality reflected in the thinking of the personal characteristics and behavior . The core meaning of personality refers to the sum of the individual with unique qualities or characteristics. Innovative personality is the power systems of innovation activities. It includes innovative emotions, the will of innovation, innovation rational three. It showed the love of innovation activities, there is a strong desire for innovation, and courage to overcome difficulties in innovation activities, indomitable fighting spirit, and to correctly determine the value of the direction and level of innovation. Differences in personality characteristics to a certain extent determines the size of the innovative achievements. Generally speaking, innovation and personality, including 
courage, honesty, independence, perseverance and meticulous, and good personality traits. College Students' Creative Personality should strive to do: to establish a new ideal, the beliefs of firm innovation, cultivate the quality of indomitable will; creative activities that must be clear goal should be a small target to target, from low to high, progressive development, it gradually to the formation of innovation and quality; three teachers in the teaching process, according to the level of student ability to make some difficult students in analysis, problem-solving processes, it the will of the innovative quality of the exercise; 40 to train students to self-monitor their own innovation process and found that the problem is corrected in a timely manner, so that innovative activity has always been able to move forward in the right direction.

\section{Practice and Exploration of an Innovative Education}

\section{A. Students innovation mechanism}

One to form an effective incentive mechanism. Change that hinder the education of teachers and students the spirit of innovation and innovative capacity development concept, the mode of education, to encourage and support top-notch, to encourage and support took the lead in efforts to come to the fore of the outstanding talents to create the conditions; the establishment of higher education capacity, learning, research integration system, linking the university to create knowledge, the dissemination of knowledge and application of knowledge of the internal functions. Specific measures include the work of colleges and teachers in creative education will be included in the annual examination content, and innovative practice activities guide students achieved outstanding results of the incentives for teachers to increase the right to participate in the competitions of all kinds of scientific and technological innovation, award-winning and innovative practice activities get the outstanding achievements of students and reward efforts.

\section{B. College students cultivate innovation environment}

Innovative education to carry out, cultivate students' creative quality, and must gradually establish and improve the soft environment and hard environment for innovative personnel training, to provide students with adequate conditions and opportunities of thinking, hands, and innovation. Only a strong campus climate for innovation and an environment conducive to innovation, to the cultivation of innovative talents.

C. Students innovative practice exercise

Innovation Education is inseparable from the full exercise of the practice of innovation, its main extracurricular scientific and technological innovation activities, students of social practice, graduation design and other forms of expanding the space of the Students' Innovative Practice.

\section{References}

[1] Liu Mo. Innovative educational theory of science and engineering students research and practice [D]. Nanjing: Nanjing University of Technology, 2005: 25.

[2] Wang Rongde. Exploration of university students' innovation education construction and practice [J]. Huzhou Teachers College, Institute, 2002 (1) : 32-34.

[3] Jin Ma. Innovation and wisdom [M]. Beijing: China Youth Press ,1991: 97 -99.

[4] Li Guangyu. Scientific and technological innovation art [M]. Beijing: Science Press, 2000: 335. 